\title{
A case study of the integrated programme for children with disabilities in mainstream child care centres in Hong Kong: Exploring the instructional strategies
}

\author{
Yuk Ching LAl
}

Department of Early Childhood Education, The Education University of Hong Kong.

E-mail: yclai@eduhk.hk.

Accepted $29^{\text {th }}$ May, 2019.

\begin{abstract}
The operation of the integrated programme for children with disabilities in mainstream early childhood settings has become a primary service option in many countries around the world, and as such the programme provides a huge benefit for the development and learning of these children. The integrated programme in Hong Kong mainstream child care centres (CCCs) has been implemented since the late 1970s with the goal of facilitating the return of children with disabilities to mainstream education and to the mainstream society. As instructional strategies (i.e. relate to aspects of the teaching strategies and curriculum) play a significant role in influencing the effectiveness of the integrated programme for children with disabilities, investigating how these aspects have been implemented in integrated classrooms is important. Two case studies consisting of interviews (semi-structured and informal interviews), observations and documentations were gathered from various stakeholders (i.e. six school stakeholders, two parents of children with disabilities and two children with disabilities). The findings indicate that the instructional strategies adopted in integrated classrooms were inappropriate and ineffective. Implications for instructional changes are discussed.
\end{abstract}

Keywords: Integrated programme, children with disabilities, mainstream child care centres, instructional strategies.

\section{INTRODUCTION}

Inclusive education, the concept that students with diverse abilities, gender, race and socio-economic backgrounds should play and learn with age-appropriate peers in all educational settings, has been gradually implemented in the world, such as in the U.K. and the U.S., since the early 1990s (Babic et al., 2018; Lai and Gill, 2017). Inclusive education advocates that all schools should respond to children's backgrounds, interests, experience, knowledge and skills (Kricke and Neubert, 2017). This global phenomenon reflects common aspirations within societies for an early intervention programme that can contribute to the holistic development and learning of children with disabilities (Lai and Gill, 2017). This approach is seen as mutually beneficial to children with and without disabilities, both of whom are learning together in an inclusive educational environment (Lai, 2018; Lai and Gill, 2017).

Given the influence of the U.K., the former suzerain of Hong Kong, and in response to increasing concerns worldwide about human rights for people with disabilities, the autonomous territory began to implement the early integration for children with disabilities in mainstream child care centres (CCCs) in 1978; it then operated the integrated programme in mainstream kindergarten in 1988 (Lai, 2018; Lai and Gill, 2017). Although inclusive education is more comprehensive and equitable than the integrated education (Kricke and Neubert, 2017), the Hong Kong government is still operating the integrated programme for children from 2 to 6 years old with a 
variety of mild-grade disabilities in mainstream CCCs with a view "to facilitate their future integration into the mainstream education as well as in the society" (Social Welfare Department, 2019).

Integration implies a commitment to human rights and equal opportunities for children with disabilities (Lai, 2018; Lai and Gill, 2014, 2017). A number of scholars believe that an integrated programme is valuable not only for children with disabilities but also for children without disabilities (Lai, 2018; Lai and Gill, 2014, 2017). However, the Hong Kong government neglected the integrated programmes in mainstream kindergartens in 2005 owing to the centralisation of resources after the unification of early childhood education (ECE) and care services (Lai, 2018; Lai and Gill, 2014). Consequently, only a small number of mainstream CCCs continued to offer the integrated programme to children with disabilities from aged 2 to 6 years old. For instance, only 216 out of 1,000 ECE organisations to operate the integrated programme during the school year 2018 to 2019 (Social Welfare Department, 2019). This indicates that the government has neglected the development of the integrated programme as well as the rights of children with disabilities, preventing them from reaping the benefits of a wide range of ECE settings (Lai, 2018; Lai and Gill, 2014). In turn, such neglect has inevitably affected the development and learning progress of children with disabilities.

In Hong Kong, each integrated group consists of six children with mild disabilities (Social Welfare Department, 2019). Thus, a special education teacher is employed to take care of each integrated group. Extra assistance, such as individualised educational programmes (IEPs) and para-medical support services (e.g. speech therapy and physiotherapy), are also provided for children with disabilities involved in the integrated programme. Meanwhile, mainstream education teachers are not required to customise the mainstream curriculum to cater for the diverse learning needs of children with disabilities. The omission of these statutory requirements reflects the academically driven culture of Hong Kong society (Lai and Gill, 2014; 2017). Hence, people living and studying in such an elitist society can have the perception that the curriculum offered to children with disabilities is inappropriate (Lai, 2018; Lai and Gill, 2017). Consequently, children with disabilities who are part of integrated educational settings consistently fail academically (Lai, 2018; Lai and Gill, 2014, 2017). Such unfair expectations and the resulting, sometimes limited, achievements of children with disabilities truly challenge the principle of integration.

For the reasons stated above, it is time to re-consider the best practices in instructional strategies (i.e. teaching strategies and curriculum) for children with disabilities studying in Hong Kong's mainstream CCCs. As most of the research on Hong Kong early integration are based on interviews with school stakeholders and parents
(Cheuk, 2007; Lai, 2018; Lai and Gill, 2014, 2017; Lee et al., 2015), there is currently a limited understanding of how the children with disabilities play and learn in a naturalist educational environment. In the present study, two case studies were conducted to determine the quality of instructional strategies of integrated programmes in Hong Kong's mainstream CCCs.

\section{Common instructional strategies for facilitating children with disabilities in integrated classrooms}

As yet, no consensus exists among different societies as to what the components of a high-quality integration programme might be, nor how the success of the integrated programme should be measured within ECE settings (Spiker et al., 2011). The principles of quality early integration vary from one society to another. Thus, several common strategies can be used to provide the best practices in instructional strategies to facilitate the development and learning of children with various disabilities in integrated CCCs. These strategies are listed below:

- Providing a loving and caring classroom atmosphere to fully include children with disabilities (Hall et al., 2014; Lai, 2018).

- The curriculum contents (i.e. mainstream and special curricula) focused on an early childhood programme should address the core features and characteristics of children with disabilities (Cook et al., 2012; Tjernberg and Mattson, 2014). In addition, the goals and objectives of each curricular area should be highly individualised for each child's developmental level as well as his/her learning strengths and weaknesses.

- Employing systematic instruction, including giving modelling, prompting, shaping, encouragement and reinforcement, to assist and encourage a child with a disability to acquire or improve skills needed for participation in natural experiences (Cook et al., 2012; Lewis et al., 2017).

- Using flexible assessment strategies to build on each child's strengths (Lai and Gill, 2017). This means that assessment must be closely tied to an interesting curriculum that uses flexible groupings, in order to give the child with a disability an opportunity to work in a variety of environments and with same-age peers.

- Requiring collaboration between mainstream and special education teachers so as to meet the needs and enhance the learning of children with disabilities within integrated classrooms (Cook et al., 2012; Lewis et al., 2017).

- Employing the transdisciplinary approach to design and work out the best programmes (e.g. IEPs) for children. This means that teachers (i.e. mainstream and special education teachers), professionals (e.g. therapists and psychologists) and parents of children with disabilities are 
required to work together in order to provide appropriate programmes that cater for the needs of children with disabilities (Cook et al., 2012; Lai, 2018).

In sum, children with different types of disabilities vary individually. Hence, they need to be educated using specific strategies because this can better accommodate and enhance their strengths. In this study, two target children with disabilities in two different mainstream CCCs with an integrated programme were studied to investigate whether the instructional strategies employed by their teachers helped them benefit from the integrated setting. In addition, school stakeholders and parents in integrated CCCs were also invited to express their views as to whether these strategies adopted by the teachers in integrated classrooms could meet the needs of these target children.

\section{METHODOLOGY}

\section{Research design}

In this study, a qualitative research employing the case study methodology was selected because as a form of research, case study can be defined "by interest in individual cases, not by the methods of inquiry used" (Stake, 2005: 443). The reasons for using case study in this research were to better understand the lives of the target children with disabilities studying in integrated CCCs, and subsequently, to better theorise on the case (Thomas, 2017).

As mentioned previously, only a few studies focused on examining how the children with disabilities play and learn in integrated classrooms. In addition, most of the research on integrated programmes were based on the interviews with school stakeholders and parents (Cheuk, 2007; Lai, 2018; Lai and Gill, 2014, 2017; Lee et al., 2015). Therefore, it is appropriate to use the case study approach to develop an account of this understanding. Through this qualitative case study, the quality of the instructional strategies adopted in integrated CCCs was revealed. Accordingly, the main research question of this study can be stated as follows:

- What are the factors that facilitate or hinder the quality of instructional strategies in integrated CCCs?

A generalisation should not necessarily be the objective and purpose of a case study (Thomas, 2017). However, to enhance the credibility of the data produced from just one site and to provide detailed information, two case studies were used in this study. In addition, to gain a comprehensive understanding of the implementation of the integrated programme in mainstream CCCs, various methods (i.e. semi-structured and informal interviews, observation and documentation) were employed in this study. These methods are described in detail below.

\section{Interviews (semi-structured and informal interviews)}

Semi-structured interview: Semi-structured interview was adopted to understand the deep experience of the school and parent stakeholders about their views on classroom practices of an integrated programme for children with disabilities in mainstream CCCs (Cohen et al., 2018). All school stakeholders and parents in integrated CCCs were asked the same questions individually. The foci of the interview schedule were as follows:

- the teaching strategies employed by both special and mainstream education teachers in integrated CCCs;

- the curriculum provided for children with disabilities in integrated CCCs; and

- the collaborative teamwork among all parties involved in offering the programmes to children with disabilities in integrated CCCs.

The interviews were recorded and the length of each interview ranged between 25 and 50 minutes, with the parents of children with disabilities requiring more time to share their views than others. All interviews were conducted in Cantonese because the first language of all interviewees was Cantonese.

Informal interview: Informal interview was held after each observation session, allowing the researcher to get to know the meanings that lie behind the observed behaviours and develop a deep understanding of each case study (Cohen et al., 2018).

\section{Observation}

The use of observation was central to the uncovering of what actually occurred in the integrated CCCs (Yin, 2014). Thus, a more complete description of live data was gathered through observing the involvement of children with disabilities and the people around them (e.g. their teachers and peers without disabilities) during school hours. This material was seen to reflect the current practices of the integrated programme and, consequently, the benefits of early integration for children with disabilities. The observation focused on the following two areas:

- pedagogical strategies in engaging children with and without disabilities.

- child-child and teacher-child interactions.

As the researcher hoped to understand the real lives of the target children with disabilities in integrated CCCs, it was proper to observe how these children were involved in the routine programmes (i.e. theme teaching, small group learning, music and physical play, art and craft, 
Table 1. Observation schedule.

\begin{tabular}{lllll}
\hline Centre A & & & Centre B \\
\cline { 1 - 2 } \cline { 5 - 5 } No & Date & No & Date \\
\hline $1^{\text {st }}$ Observation & 17 May 2018 (Thursday) & & $1^{\text {st }}$ Observation & 16 May 2018 (Wednesday) \\
$2^{\text {nd }}$ Observation & 12 June 2018 (Tuesday) & & $2^{\text {nd }}$ Observation & 15 June 2019 (Friday) \\
\hline
\end{tabular}

free play and IEP). To gain a holistic picture of what programmes were offered to each target child with a disability in an integrated classroom, the researcher made all the visits on different days in different weeks over a period of one month between mid-May 2018 and mid-June 2018. The researcher made a whole-day (from 9 am to $5 \mathrm{pm}$ ) visit to each integrated CCC during the routine programmes.

Finally, two days were arranged by the researcher to attend the routine programmes in each of the participating CCCs. In other words, a total of four visits were made to observe the routine programmes in both integrated CCCs (Centre A and Centre B) between midMay 2018 and mid-June 2018. The detailed schedules of the observations for each centre are listed in Table 1.

During the observations, the researcher acted as a teaching assistant so that she could get in touch with the target children and the people around them. A running record was used to capture all information observed by the researcher.

\section{Documentation}

Documentation comprises the strategies and procedures for analysing and interpreting documents in a particular area of the study (Cohen et al., 2018). In this study, the IEPs and progress reports of the target children with disabilities were analysed to provide information about the current practices of integration and the progression of children with disabilities in mainstream CCCs. All of these used documents were used within the school year 201718.

\section{Participants}

To promote the fairness of the selection as well as enhance the credibility of this case study, 'purposeful random sampling' was employed to recruit both the participating integrated CCCs and participants (interviewees and target children with disabilities).

\section{Participating integrated CCCs}

In Hong Kong, all mainstream CCCs implementing the integrated programme are a) regulated by the Education Bureau for its mainstream services and managed by the
Social Welfare Department (SWD) for its integrated services, b) either operated by religious or charitable organisations, and c) required to admit a group of six children aged 2 and 6 years old with mild disabilities and various aetiologies (a special education teacher was employed to take care of the group). These two participating centres were randomly selected from a list of eligible integrated CCCs downloaded from the official website of the SWD. To obtain rich information from the integrated CCCs, the chosen centres were those that had operated the integrated programme for at least two years. Details of these integrated CCCs are shown in Table 2.

\section{Interviewees}

The interviewees of this study included the school stakeholders and parents of children with disabilities involved in the integrated programme. All interviewees with at least two years of experience in the integrated programme were invited to be interviewed to ensure that they shared meaningful information. Accordingly, only one participant of each sub-targeted group was selected randomly to participate in the interview in order to ensure the fairness of selection. Details of the compositions of the school stakeholders and parents are shown in Table 3 and 4, respectively.

Accordingly, six school stakeholders and two parents of children with disabilities were interviewed. The profiles of the school stakeholders and parents are listed in Table 5 and 6 , respectively.

\section{The target children for observation}

In each integrated CCC, with parental formal consent, one child with a disability who was part of the integrated programme was observed. The nature of the disabilities of the target children can be found in Table 7 .

\section{Data analysis}

The taped interviews, observation notes and the information from documentation were transcribed in Chinese, and selected extracts were translated into English. After completing the transcription and translation, 'topic coding' was first used to interpret data gained from interviews, documentations and observations 
Table 2. Information about the participating integrated CCCs.

\begin{tabular}{|c|c|c|}
\hline & Centre A & Centre B \\
\hline Establishment & 1980s & $1990 s$ \\
\hline District & New Territories West & Kowloon West \\
\hline Type of housing & Public housing & Private housing \\
\hline Socio-economic status of this area & Lower & Middle \\
\hline Services provided in the centre & $\begin{array}{l}\text { - Kindergarten education } \\
\text { - Integrated programme } \\
\text { - Occasional child care service }\end{array}$ & $\begin{array}{l}\text { - Kindergarten education } \\
\text { - Integrated programme } \\
\text { - Occasional child care service } \\
\text { - Extended hours service }\end{array}$ \\
\hline Affliction & Religious organisation & Charity organisation \\
\hline Number of full-time staff & 21 & 24 \\
\hline Number of students & 110 & 120 \\
\hline Number of integrated group & 1 (six students) & 1 (six students) \\
\hline
\end{tabular}

line by line respectively (Richards, 2015). A list of the topics and sub-topics is presented based on the foci of the interview schedule and observation.

Then, 'analytical coding' was performed to further interpret, reflect on and refine the meanings being coded (Richards, 2015). Concept themes emerged based on the topics coded previously (Richards, 2015). The themes and sub-themes also captured from the interview, documentation and observation data were developed (Cohen et al., 2018).

\section{Trustworthiness}

'Peer debriefing' was employed to enhance the trustworthiness of the study. In detail, a critical friend of the researcher who was an expert in inclusive/integrated education was invited to conduct a debriefing session after the completion of the analysis. The expert helped to investigate whether the researcher overemphasised or underemphasised a point of the data (Richards, 2015).

\section{RESULTS AND DISCUSSION}

The findings gained from the interviews, documentations and observations revealed that the quality of the instructional strategies adopted in integrated CCCs were ineffective and inappropriate.

\section{Inappropriate curriculum}

The analysis presented in this study revealed that the special and mainstream curricula for children with disabilities in integrated CCCs were inappropriate:

\section{Inappropriate mainstream curriculum}

The study found that both target children had to follow the same curriculum as children without disabilities did in the mainstream class (CentreA_1stObservation_9:40, $2^{\text {nd }}$ Observation_9:50; CentreB_1stObservation_9:30, $2^{\text {nd }}$ Observation_9:45); this was too difficult for children with disabilities, as the mainstream education teachers in both centres stated:

Frankly speaking, the mainstream curriculum is difficult for children with disabilities. They, therefore, become less interested in learning... (Interview_CentreA_Mainstream Education Teacher $\mathrm{Ma})$

The mainstream curriculum is too hard for children with disabilities. It weakens their confidence... (Interview CentreB Mainstream Education Teacher Lau)

As stressed by Lai and Gill $(2014,2017)$, because of the weakness of children with disabilities, these children are difficult to meet the standards of the mainstream curriculum. Under this circumstance, children with disabilities are not accepted by the people around them (e.g. their mainstream education teachers and parents of children without disabilities) in integrated classrooms (Lai, 2018; Lai and Gill, 2017).

In addition, the contents and activities of mainstream curriculum in both centres seemed traditional, uninteresting, teacher-directed and academic. For instance, every day, Ming in Centre A was required to do homework consisting of exercises in writing Arabic numbers, Chinese characters and English letters (CentreA_1 ${ }^{\text {st }}$ Observation_11:45,

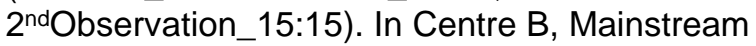


Table 3. Composition of participants - School stakeholders.

\begin{tabular}{|c|c|c|c|}
\hline & & $\begin{array}{l}\text { Integrated Child Care } \\
\text { Centre A (Centre A) }\end{array}$ & $\begin{array}{l}\text { Integrated Child Care } \\
\text { Centre B (Centre B) }\end{array}$ \\
\hline \multirow[t]{2}{*}{ Principal } & & 1 person & 1 person \\
\hline & Special education teacher & & \\
\hline \multirow[t]{3}{*}{ Teachers } & $\begin{array}{l}\text { S/he is the special education teacher of the } \\
\text { target child with a disability and has at least two } \\
\text { years of experience in teaching the integrated } \\
\text { programme }\end{array}$ & 1 person & 1 person \\
\hline & Mainstream education teacher & & \\
\hline & $\begin{array}{l}\text { S/he is the mainstream education teacher of the } \\
\text { target child with a disability and has at least two } \\
\text { years of experience in teaching children in } \\
\text { mainstream classrooms }\end{array}$ & 1 person & 1 person \\
\hline
\end{tabular}

\#Selection criteria

Table 4. Composition of participants - Parents of children with disabilities.

\begin{tabular}{|c|c|c|c|}
\hline & & $\begin{array}{l}\text { Integrated Child Care } \\
\text { Centre A (Centre A) }\end{array}$ & $\begin{array}{l}\text { Integrated Child Care } \\
\text { Centre B (Centre B) }\end{array}$ \\
\hline & Parent of a child with a disability & & \\
\hline Parents & $\begin{array}{l}\text { S/he is the parent of the target child with disability. Her/his child } \\
\text { has at least two years of experience in an integrated } \\
\text { programme } \#\end{array}$ & 1 person & 1 person \\
\hline $\begin{array}{l}\text { Sub- } \\
\text { total }\end{array}$ & & 1 interviewee & 1 interviewee \\
\hline Total & & \multicolumn{2}{|c|}{2 interviewees } \\
\hline
\end{tabular}

"Selection criteria

Education Teacher Lau spent most of the school days in academically oriented programmes, for example, in English and Chinese language and in mathematical calculations (CentreB_1stObservation_10:00, 12:45,

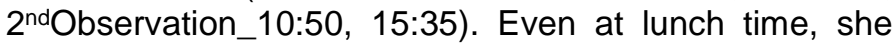
also asked the children to count from 1 to 100 or to work on simple mathematical calculations when they were

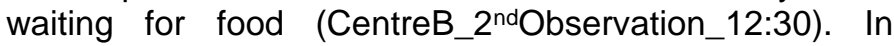
order to produce more fun and interesting lessons for children with disabilities to learn, mainstream education teachers should use play as a context for learning (Goldstein, 2012; Tsao, 2008).

As children with disabilities failed to achieve the required academic performance in mainstream classrooms, parents of the target children were not satisfied with the mainstream curriculum employed to teach their children, stating that:

My son is...always required to do the worksheets during the PE lessons. I requested his class teacher to spend some time in teaching him after lunch. However, she told me that she could not teach my son because she was the only one who taught the class...I was disappointed. (Interview_CentreA_Target Child Ming's mother).

The class teacher of my son is not quite good. The curriculum seems very difficult for him. As such, the class teachers always complain that the English pronunciation of my son remains poor... (Interview_CentreB_Target Child Tim's mother)

Since educational equity and quality for all children regardless their abilities have been promoted in the worldwide (Lee and Manzon, 2014), the mainstream education teachers should modify the curriculum to accommodate the needs and developmental stage of each child (Lai, 2018; Lai and Gill, 2017).

\section{Inappropriate special curriculum - IEPs}

During the school year 2017-18, the IEPs provided for the target children did not meet their needs and specific 
Table 5. Profiles of the school stakeholders $(\mathrm{N}=6)$.

\begin{tabular}{|c|c|c|}
\hline Parameter & $\mathbf{n}$ & $\%$ \\
\hline \multicolumn{3}{|l|}{ Gender } \\
\hline Female & 6 & 100 \\
\hline \multicolumn{3}{|l|}{ Age (years) } \\
\hline $26-30$ & 1 & 16.7 \\
\hline $31-35$ & 1 & 16.7 \\
\hline $36-40$ & 0 & 0 \\
\hline $41-50$ & 2 & 33.3 \\
\hline $51-60$ & 2 & 33.3 \\
\hline \multicolumn{3}{|l|}{ Ethnicity } \\
\hline Chinese & 6 & 100 \\
\hline \multicolumn{3}{|c|}{ Language spoken at home } \\
\hline Cantonese & 6 & 100 \\
\hline \multicolumn{3}{|c|}{ Highest qualification } \\
\hline Master & 1 & 16.7 \\
\hline B.Ed. & 4 & 66.7 \\
\hline Higher Diploma & 1 & 16.7 \\
\hline \multicolumn{3}{|c|}{ Teaching experience (years) } \\
\hline $5-10$ & 2 & 33.3 \\
\hline $11-15$ & 1 & 16.7 \\
\hline $16-20$ & 1 & 16.7 \\
\hline $21-25$ & 2 & 33.3 \\
\hline \multicolumn{3}{|c|}{ Qualification of early childhood special education training } \\
\hline Yes & 3 & 50 \\
\hline No & 3 & 50 \\
\hline
\end{tabular}

Table 6. Profiles of the parents of children with disabilities $(\mathrm{N}=2)$.

\begin{tabular}{lll}
\hline Parameter & $\mathbf{n}$ & $\%$ \\
\hline $\begin{array}{l}\text { Gender } \\
\text { Female }\end{array}$ & 2 & 100 \\
& & \\
Age (years) & 1 & 50 \\
$31-35$ & 1 & 50 \\
$36-40$ & & \\
Ethnicity & 2 & 100 \\
Chinese & & \\
Language spoken at home & 2 & 100 \\
Cantonese & & \\
Highest qualification & 2 & 100 \\
Secondary & & \\
\hline
\end{tabular}

developmental stages. For instance, both children in two centres were only offered one-on-one IEP training programmes, in which they did not have enough opportunities to learn and develop social skills with peers through cooperative learning (CentreA_IEP Long- and Short-Term Objectives; Centre B_IEP_Long- and ShortTerm Objectives). In fact, the special education teachers in both centres knew that the target children always played alone and sometimes refused to cooperate (CentreA_ProgressReport 1-2; CentreB_ProgressReport 2-3). Thus, teachers in integrated educational settings must promote the social development of children, especially those suffering from the autistic spectrum disorder (ASD) (Cook et al., 2012).

The contents of the IEPs in both centres did not meet the developmental needs of the target children mainly because the learning goals and contents of these IEPS were just being repeated. For example, Special Education Teacher Lo in Centre A kept teaching the same content like asking questions during the 5-day 
Table 7. Nature of the disabilities of the target children.

\begin{tabular}{llll}
\hline $\begin{array}{l}\text { Integrated CCC } \\
\text { (Name of the target child) }\end{array}$ & Child's sex & Child's age & Nature of the child's disabilities \\
\hline $\begin{array}{l}\text { Centre A } \\
\text { (Ming) }\end{array}$ & M & $5 \& 1 / 2$ & Developmental delay \\
$\begin{array}{l}\text { Centre B } \\
\text { (Tim) }\end{array}$ & M & 5 & $\begin{array}{l}\text { Autistic spectrum disorder and mild } \\
\text { intellectual disabilities }\end{array}$ \\
\hline
\end{tabular}

* Remark: M (Male)

practice even though the target child, Ming, already completed all the targeted training skills for the first day over the three trials (CentreA_1stObservation_11:09). Meanwhile, Special Education Teacher Fu in Centre B asked the target child, Tim, to repeat scooping small beads with a spoon and pouring the beads into a wooden bowl during the 10 consecutive days (CentreB IEP 413). Training like this would reduce the motivation of children with disabilities to learn because they already developed the skills required. In this connection, the literature has noted that new goals and objectives must be added to the IEPs from time to time if the child with a disability has already attained the targeted goals and objectives (Cook et al., 2012; Kirk et al., 2006). In other words, the achieved goals and objectives must be removed from time to time so that a new training plan can be provided for the purpose of further developing the skills of children with disabilities.

In addition, as a child with ASD and mild-grade intellectual disabilities, Tim, showed limited cognitive ability, and the contents of each training session were quite hard for him. In the school year 2017-18, except for five training sessions consisting of two learning goals related to two developmental domains (CentreB_IEP 1620 ), the rest had three learning goals related to three developmental domains. As many learning items were included in each training session, Tim found learning difficult and even rejected it (CentreB_1 ${ }^{\text {st }}$ Observation_12:25-12:55). In view of this, scholars suggest that the contents of the IEPs be made to be neither too easy nor too hard (Alston and Kilham, 2004; Cook et al., 2012). The IEPs must be planned and modified based on the needs and learning level of a child with a disability (Hall et al., 2014; Kirk et al., 2006).

\section{Lack of collaboration between special and mainstream education teachers}

The researcher found that the IEPs in the two Centres did not really correspond to the mainstream curriculum. For instance, the progress report in the mainstream programme showed that Ming had competence in cutting out shapes in Term 1 from September 2017 to January 2018 (CentreA_Progress Report 5), but Special
Education Teacher Lo kept practising cutting in the IEPs for one and a half months (i.e. from February to midMarch 2018) (CentreA_IEP 32-34). This indicated that the collaboration between special and mainstream education teachers did not seem to communicate with one another on the issue of teaching children with disabilities. The cooperation between special and mainstream education teacher was weak. The special education teachers in both integrated CCCs told the researcher that they did not have any regular meetings about the progress of children with disabilities (Interview_CentreA_Special Education Teacher Lo; Interview_Centre $\bar{B}$ _Special Education Teacher $\mathrm{Fu}$ ). Also, the mainstream education teacher in Centre A:

...I have no idea about the contents of the student's IEP. Also, I don't think the special class teacher know our curriculum because we don't have any regular meetings... (Interview_CentreA_Mainstream Education Teacher Ma)

This contradicted the advice from the Hong Kong SWD that special education teachers in integrated CCCs must communicate and cooperate with their colleagues to ensure the provision of good service for each child with a disability (Social Welfare Department, 2001). The literature also indicates that special education teachers in integrated educational settings should develop a mutual sharing with mainstream education teachers (Cook et al., 2012). In addition, mainstream and special education teachers should work closely to provide a constructive, positive and healthy curriculum for children with disabilities (Lewis et al., 2017). This would help meet the needs and promote the learning of children with disabilities in integrated classrooms (Cook et al., 2012; Lewis et al., 2017).

\section{Inadequate collaboration among teachers, professionals and parents}

The Hong Kong SWD stresses that parents or families of children with disabilities should train their children at home using programmes designed by special education teachers (Social Welfare Department, 2001). Thus, the 
special education teachers in Centre A and Centre B also provided weekly home training exercises, which mainly incorporated the suggestions made by the professionals (e.g. speech therapists and occupational therapists) for all children, including the two target children in the integrated group. In order to help the parents of children with disabilities learn the skills necessary to teach their children at home, the special education teachers provided face-to-face explanations and even demonstrations for them every Friday (CentreA_Home TrainingRecords 1-30; CentreB_HomeTrainingRecords 135). The parents of the target children felt that, even after talking with special education teachers about the home training exercises, they still did not understand how to train their children at home (CentreA_Informal Interview1_Target Child Ming's father and mother; CentreB_Informal Interview2_Target Child Tim's father). However, Principal Wong in Centre A felt that the special education teacher could not convey the messages provided by the therapists to parents clearly and accurately because of their insufficient professional knowledge (Interview_CentreA_Principal Wong). This can be attributed to the fact that the home training exercises were the follow-up exercises suggested by the therapists who did not have any discussions with other professionals and special education teachers in advance (CentreA_Informal Interview_Special Education Teacher Lo). Previous research has also found that since the therapists only provided suggestions to special education teachers to train children with disabilities, these children could only learn from a 'second-hand curriculum' from the special education teacher (Lai, 2018). The quality of the curriculum is affected.

Therefore, parents of the target children were unsatisfied with the IEPs offered to their children, stating that:

I don't know too much about the IEPs...I only know that...Ms Lo always teaches my son how to write English words and Chinese characters and seldom explains to him the meanings of these words. However, his English and Chinese language skills are still very weak. (Interview_CentreA_Target Child Ming's mother)

The special class teacher seldom invited me to sit in the IEPs. I know very little about the IEPs...I think that the IEPs did not really help my son because the aims of the IEPs are supposed to help my son do the revisions. (Interview_CentreB_Target Child Tim's mother)

In order to provide quality programmes and activities for every child with a disability in integrated CCCs and strengthen the learning styles and needs of each of the child with a disability, scholars suggest that the IEPs including the home training activities be developed through active collaborations among professionals (i.e. psychologists and therapists), teachers (i.e. special and mainstream education teachers) and parents of the children with disabilities (Hall et al., 2014; Lai 2018).

\section{Insufficient child-child and teacher-child interaction}

Aside from the memorisation of numbers, mathematical calculations and writing Chinese characters and English words, the mainstream activities held were mostly individual-based such as 'toy and library time', 'painting and teaching aids time', and 'music and $P E$ ' (CentreA_1 ${ }^{\text {st }}$ Observation_10:15, 11:50, 15:30, 16:55, $2^{\text {nd }}$ Observation_10:26, $\quad 11: 30, \quad 16: 05, \quad 16: 15$; CentreB_1stObservation_10:45; $11: 35, \quad 16: 00$, $\left.2^{\text {nd } O b s e r v a t i o n \_10: 55, ~} 11: 45,15: 05,16: 25\right)$. Scholars, such as Goldstein (2012) and Sussman (2012), state that children can practice their problem-solving skills and cooperativeness in groups and enjoy the fun of learning through play-based activities. Hence, instead of asking children to sit on their chairs for a long time to work on pre-academic exercises, teachers may embed preacademic concepts into play-based exercises. Under this proper teaching strategy, teachers can create more interactions for children with or without disabilities, especially those with ASD like Tim in Centre B, as the deficits of these children include communication and social delays.

In addition, the mainstream education teachers had few interactions with the children. For instance, when the children were asked to work on the in-class assignments, both the mainstream education teachers in Centre $A$ and Centre $B$ only spent time marking papers (CentreA_1 ${ }^{\text {st }}$ Observation_11:42, $\quad 2^{\text {rd }}$ Observation_15:38;

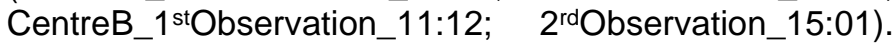
In order to enhance teacher-child interaction, Alston and Kilham (2004) have suggested that teachers must travel through all areas where children are working and express personal regard for all children in the integrated classrooms.

\section{Improper teaching strategies}

Sometimes, the target children raise their hands to answer questions but the mainstream education teachers rarely chose them to answer (CentreA_1stObservation_10:00, $2^{\text {nd }}$ Observation_12:30;

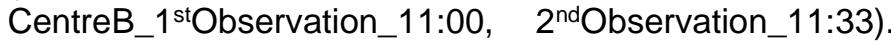
Instead, negative attention was always given to these target children and others. For example, Mainstream Education Techer $\mathrm{Ma}$ in Centre $\mathrm{A}$ always instructed the children by saying "Keep quiet!", "Be quick!", "Sit down please!" and "Stop it!" (CentreA_1stObservation_9:25, $11: 05,11: 44,15: 17,16: 02 ; 2^{\text {nd }}$ Observation_10:12, 10:38, 11:37, 16:04), whereas Mainstream Education Teacher Lau in Centre B always reminded "Tim, stop playing with the pencil, otherwise I will take it away!", "Tim, you should 
sit well and don't stretch your leg out of the desk!" and "Tim, don't raise your voice!" were examples of negative comments offered over time (CentreB_1 ${ }^{\text {st }}$ Observation_10:30, 10:50, 11:19, 15:27;

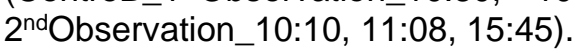

Studies have also shown that, sometimes, disruptive behaviours are triggered if children try to seek attention from the teachers (Cook et al., 2012). Thus, teachers must be able to give positive attention rather than negative so as to promote the pro-social behaviour of children (Hall et al., 2014; Kirk et al., 2006). Therefore, the mainstream education teachers needed to explain why children should or should not do certain things when they were giving negative feedback. Thus, children would not understand the reason why they should not do something and how they should behave in class, but would simply learn to follow instructions passively. Therefore, in order to provide appropriate moral concepts to children with and without disabilities, teachers must utilise such opportunities to teach the children important lessons, such as why people have to follow rules, why they must be considerate to others if loud talking is disturbing the class, and so on (Kirk et al., 2006).

\section{CONCLUSION AND RECOMMENDATIONS}

To conclude, the analysis of findings reveals that the instructional strategies adopted in integrated CCCs in Hong Kong were inappropriate and ineffective. The quality of the integrated programme operating in mainstream CCCs was seen to operate in less than optimum ways in terms of fostering the learning and development of children with disabilities. Consequently, children with disabilities cannot fully benefit from their integrated CCCs. So, the instructional strategies of the integrated programme must be changed if it is to work as intended. Some recommendations are made below:

\section{Providing appropriate curriculum}

The findings strongly suggest that the mainstream education teachers should provide an appropriate curriculum for the individual child to enhance their ability and strengths. The mainstream education teachers should also modify the curriculum to suit the needs and developmental stage of each child (Lai, 2018; Lai and Gill, 2017). This also ensures the quality of the curriculum and educational equity and for all children regardless their abilities (Lee and Manzon, 2014).

In addition, the special and mainstream curricula provided for children with disabilities must be re-focused on play-based activities rather than forcing the children to learn academically. This is because all children, including children with disabilities, can explore the mysteries of both the physical and social worlds through participating in play-based programmes (Sussman, 2012). Therefore, play-based activity with peers is a fundamental and effective intervention curriculum that enhances the wellrounded development of children with disabilities, especially the children with ASD (Tsao, 2008). Hence, all children, including, children with disabilities can be encouraged to select their activities according to their own interests and learn through play (Barnett, 2018).

Moreover, studies have well documented that the assessments arranged for children with disabilities in integrated classrooms should be closely linked with the mainstream curriculum so as to keep track of the learning and development of the children who have disabilities (Cook et al., 2012; Lai, 2018; Lai and Gill, 2017). Doing so can help monitor the appropriateness of the programmes offered to each of a child with a disability.

\section{Increasing the child-child and teacher-child interactions}

Evidence from this study suggests that the special and mainstream education teachers in integrated CCCs must be able to provide various chances for children with disabilities to interact with their peers without disabilities (Cook et al., 2012). Hence, the programmes arranged for the children with disabilities should not only be one-onone, but also be formed as small group activities.

As stated by Coelho et al. (2019), teacher-child interactions can help promote the learning and development of children in integrated educational settings. Therefore, in order to enhance teacher-child interactions, teachers must offer personal concern where children are playing and working (Alston and Kilham, 2004). In addition, the context of the curriculum should also provide opportunities allowing the children with disabilities to interact with significant adults, such as their teachers in order to promote children's social and task mastery (Cook et al., 2012).

\section{Utilising systematic instructions}

The analysis shows that all stakeholders in integrated CCCs should provide love and care for every child and embrace the unique needs of each one of them (Lai, 2018). This helps children develop a sense of belonging and boost self-esteem of children with disabilities in learning. Also, teachers should use questioning, explaining, cueing, prompting, demonstrating and/or modeling to encourage children with disabilities to complete their activities in integrated classrooms (Cook et al., 2012; Lewis et al., 2017). This helps increase the ability of children with disabilities to perform positive behaviours and promote their self-confidence, which in turn, can help to reach individual goals smoothly (Lewis et al., 2017). 


\section{Promoting collaboration between special and mainstream education teachers}

The findings suggest that special and mainstream education teachers should develop mutual curriculum goals for children with disabilities and share the use of resources so as to enhance the quality of teaching and learning (Lai and Gill, 2017). In order to ensure the appropriateness of the mainstream curriculum and IEPS offered to each child with a disability, special and mainstream education teachers must work collaboratively and closely (Lewis et al., 2017).

\section{Adopting the transdisciplinary approach}

The findings in this study reflect that in order to provide quality special curriculum (i.e. IEPs and home training) to children with disabilities in integrated CCCs, the transdisciplinary approach should be adopted (Cook et al., 2012; Lewis et al., 2017). This means that teachers (e.g. special and mainstream education teachers), professionals (e.g. psychologists and therapists) and parents of children with disabilities must work together to plan for an appropriate curriculum and trainings for the child with a disability. Their participation in curriculum planning can enhance the quality of the curriculum offered to children with disabilities (Cook et al., 2012; Lewis et al., 2017).

\section{LIMITATIONS OF THE STUDY AND RECOMMENDATIONS FOR FURTHER RESEARCH}

A limitation of the study is the low number of participating integrated CCCs and participants, such as the target children with disabilities. In addition, observing the target children with disabilities was also done in a short period of time. However, as the data were obtained from various stakeholders (i.e. principals, teachers and parents) and thus different methods (i.e. interviews, observations and documentations), this case study can surely yield rich information (Cohen et al., 2011) and ensure the reliability and validity in the analysis. The findings of this study are significant for future research in the area of early integration.

Future studies, such as longitudinal case studies with more participating integrated CCCs and target children with disabilities, may obtain more useful information about the integrated pedagogy for children with disabilities in mainstream CCCs. Except for this, a case study of enhancing cooperative behavior of children with ASD in mainstream CCCs through play-based activities with peers, may gain valuable information about how the playbased activities influence the cooperative behavior of ASD children in integrated classrooms.

\section{REFERENCES}

Alston J, Kilam C (2004). "Adaptive education for students with special needs in the inclusive classroom". Austr. J. Early Childhood 29(3):2433.

Babic DP, Simic N, Friedman E (2018). "School-level facilitators of inclusive education". Eur. J. Special Needs Educ. 33(4):449-465.

Barnett JH (2018). "Three evidence-based strategies that support social skills and play among young children with autism spectrum disorders". Early Childhood Educ. J. 46(6):665-672.

Cheuk J (2007). "Teachers' perceptions of integrated kindergarten programs in Hong Kong". Early Child Dev. Care 177(4):417-432.

Coelho V, Cadima J, Pinto Al (2019). "Child engagement in inclusive preschools: Contributions of classroom quality and activity setting". Early Educ. Dev. doi: 10.1080/10409289.2019.1591046.

Cohen L, Manion L, Morrison K (2018). Research methods in education (8th ed.). New York: Routledge.

Cook RE, Klein MD, Chen D (2012). Adapting Early Childhood Curricula for Children with Special Needs $\left(8^{\text {th }}\right.$ ed.). Boston MA: Pearson.

Goldstein J (2012). "Play in children's development, health and wellbeing". $\quad$ http://www.ornes.nl/wp-content/uploads/2010/08/Play-inchildren-s-development-health-and-well-being-feb-2012.pdf. Accessed April 21, 2019.

Hall GE, Quinn LF, Gollnick DM (2014). Introduction to teaching: Making a difference in student learning. Canada: Sage Publications.

Kirk SA, Gallagher JJ, Anastasiow NJ, Coleman MR (2006). Educating exceptional children (11 $1^{\text {th }}$ ed.). Boston: Houghton Mifflin Company.

Kricke M, Neubert S (2017). "Inclusive Education as a Democratic Challenge - Ambivalences of Communities in Contexts of Power". Educ. Sci. doi: 10.3390/educsci7010012.

Lai YC (2018). "Invisible fathers' voices about the integrated programme implemented in mainstream child care centers in Hong Kong: Implications for educational change". Educ. Rev. doi: 10.1080/00131911.2018.1481017.

Lai YC, Gill J (2014). "Multiple Perspectives on Integrated Education for Children with Disabilities in the Context of Early Childhood Centres in Hong Kong". Educ. Rev. 66(3):345-361.

Lai YC, Gill J (2017). "The Benefits and Challenges of the Integrated Programme for Children with Disabilities in Mainstream KindergartenCum-Child Care Centres in the Hong Kong Special Administrative Region: Implications for Social Change". Early Years: An Int. Res. J. doi:10.1080/09575146.2017.1369937.

Lee LMF, Yeung AS, Tracey, D, Barker K (2015). "Inclusion of children with special needs in early childhood education: What teacher characteristics matter?" Topics in Early Childhood Special Educ. 35(2):79-88.

Lee WO, Manzon M (2014). "The Issue of Equity and Quality of Education in Hong Kong". The Asia-Pacific Educ. Researcher 23(4):823-833.

Lewis RB, Wheeler JJ, Carter SL (2017). Teaching students with special needs in general education classrooms $\left(9^{\text {th }}\right.$ ed.). Boston: Pearson.

Richards L (2015). Handling qualitative data: A practical guide ( $3^{\text {rd }}$ ed.). London: Sage Publications.

Social Welfare Department (2001). An operational guide to child care centres operating an integrated programme for disabled children (in Chinese). Hong Kong Special Administrative Region Government: Printing Department.

Social Welfare Department (2019). Integrated programmes in $\mathrm{Kg}$ Cum-Child Care Centres. https://www.swd.gov.hk/storage/asset/section/376/tc/lP_112017.pdf. Accessed May 11, 2019.

Spiker D, Hebbeler, KM, Barton LR (2011). Measuring quality of ECE programs for children with disabilities. In M. Zaslow, I. Martinez-Beck K. Tout, \& T. Halle (Eds.), Quality measurement in early childhood settings Baltimore, MD: Brookes. pp. 229-256.

Stake RE (2005). Qualitative case studies. In N. K. Denzin, \& Y. S. Lincoln (Eds.), The SAGE handbook of qualitative research $\left(3^{\text {rd }}\right.$ ed.) Thousand Oaks, Cailf: SAGE Publications. pp. 443-466.

Sussman KS (2012). "The importance of play in the preschool classroom". Texas Child Care Quarterly, 36(3). https://www.ucy.ac.cy/nursery/documents/ThemaVdomadas/the_imp ortance_of_play.pdf, accessed May 11, 2019. 
Tjernberg C, Mattson EH (2014). "Inclusion in practice: A matter of school culture". Eur. J. Special Needs Educ. 29(2):247-256.

Thomas G (2017). "Progress in social and educational inquiry through case study: Generalization or explanation?". Clin. Soc. Work J. 45(3):253-260.

Tsao L (2008). "Social, language, and play behaviors of children with autism". Behavioral Dev. Bulletin, 14:40-51.
Yin RK (2014). Case study research: Design and methods ( $5^{\text {th }}$ ed.). Los Angeles: SAGE Publications.

http://sciencewebpublishing.net/jerr 